\title{
DE LA CULPA INDELEBLE A LA JUSTICIA EN LA ORESTÍA DE ESQUILO
}

\author{
FROM THE ENDELEBLE GUILT TO JUSTICE BY \\ THE ORESTEIA OF AESCHYLUS
}

\author{
Carlos Alberto Castrillón Ramírez* \\ Juan Manuel Acevedo Carvajal ${ }^{\star *}$
}

Castrillón R. Carlos A. Acevedo C. Juan M. Sophia Nº 7 - 2011. ISSN: 194-8932 Págs. 67-74.

Recepción: Junio 20 de 2011

Aceptación: Agosto 1 de 2011

\section{RESUMEN}

La cultura occidental, tal y como la conocemos, tiene su origen en la antigua cultura griega, de los griegos heredamos los principios morales que rigen a la sociedad moderna, pero dichos principios no siempre fueron racionales, algunos de ellos encontraron su fundamento en la mitología y en las creencias religiosas de los helenos. El presente articulo presenta la discusión moral entre lo divino y lo humano, a partir de los preceptos de Vergüenza y Culpa que se evidencian en La Orestía de Esquilo, y que tienen como correlato la posterior cultura de la culpabilidad instaurada por el cristianismo.

Vergüenza, culpa, justicia, khátharsis, ate.

\section{PALABRAS CLAVE}

\section{ABSTRACT}

Western culture, as we know it, has its origins in ancient Greek culture. The moral principles governing modern society were inherited from the Greeks, but these principles were not always rational; some of them are based on the mythology and religious beliefs of the Hellenes. This article presents the moral debate between the divine and the human, from the precepts of shame and Guilt evidenced by Aeschylus' in "The Oresteia", and their correlation with the subsequent culture of guilt established by Christianity.

Shame, guilt, justice, catharsis, ate.

\section{KEY WORDS}

* Magister en Literatura de la Universidad Tecnológica de Pereira, Licenciado en Lingüística y Literatura de la Universidad del Quindío, Profesor del programa de Español y Literatura de la Universidad del Quindío y de la Maestría en Literatura de la Universidad Tecnológica de Pereira. Director de la línea de investigación en "Relecturas del Canon Literario" (Universidad del Quindío) e integrante del Grupo de Investigación en Didáctica de la Lengua Materna y la Literatura (Dilema) sonorilo@yahoo. com - Carrera 15 Calle 12 Norte. Armenia, Quindío, Colombia.

** Magister en Literatura de la Universidad Tecnológica de Pereira, Licenciado en Filosofía y Letras de la Universidad de Caldas. Asesor de investigaciones de la UGCA. Integrante del grupo de investigación PAIDEIA (categoría A). asesorpublicaciones@ ugca.edu.co - Avenida Bolívar 7-46 Armenia, Quindío, Colombia. 


\section{INTRODUCCIÓN}

En su famoso estudio Los griegos y lo irracional, Eric $R$. Dodds asume el análisis de la mentalidad del hombre griego, su influencia innegable en el desarrollo de las sociedades modernas y las diferencias entre esa mentalidad y la que con base en ella se ha consolidado como característica del hombre occidental. La tesis fundamental del estudio es cuestionar la creencia general acerca del pensamiento griego como un pensamiento básicamente racional acerca de todos los aspectos de la vida, el comportamiento humano y la concepción del mundo. Dodds encuentra que existe un componente "irracional" en el modo griego de ver el mundo, cercano a la religión y a la superstición.

En ese contexto, surge la discusión acerca de las diferencias entre las culturas de vergüenza y de culpabilidad, entendidas como representaciones en las que caben los actos humanos. Proponemos en estas notas la lectura del conflicto en La Orestía de Esquilo a la luz de esas dos formas de concebir las relaciones entre lo humano y lo divino.

\section{LA CULTURA DE VERGÜENZA}

La cultura de vergüenza corresponde a la concepción homérica, ampliamente ejemplificada en la Iliada; la cultura de culpabilidad corresponde a la "actitud religiosa de la época arcaica" (Dodds, 1997: 40), como desarrollo y transformación de las ideas homéricas. Esta no es, por supuesto, una división claramente delimitada, ni siquiera temporal, pues, como advierte Dodds, son muchos y muy complejos los casos de superposición de ambas actitudes hacia el mundo y la moral social y personal.

La cultura de vergüenza concibe las actitudes humanas irracionales como el producto de fuerzas sobrenaturales muy diversas, con frecuencia arbitrarias, que determinan las acciones humanas y se convierten así en fenómenos psíquicos reales. En este sentido, toda moral entendida como norma colectiva, deriva del juicio social acerca de los actos humanos más que de algún criterio individual que oriente el comportamiento por sí mismo. Los dioses son, evidentemente, los portadores de esa visión total dentro de la cual cada comportamiento adquiere algún sentido. Sin embargo, los hombres no se sienten oprimidos por los dioses ni la voluntad divina se establece como fuerza abstracta que castiga los crímenes humanos. Como lo define Nietzsche en El origen de la tragedia:

La distancia entre lo humano y lo divino es inmensa; por ello lo que procede es la sumisión y la resignación más hondas. La auténtica virtud es la swjrouuh [cordura], [cordura], en realidad una virtud negativa. La humanidad heroica es la más noble de todas, sin aquella virtud; su destino demuestra aquel abismo insalvable. Apenas existe la culpa, sólo una falta de conocimiento sobre el valor del ser humano y sus límites (Nietzsche, 1973: 74).

Por ejemplo, al comienzo de la llíada, Agamenón, máximo comandante de los griegos, pone en riesgo la guerra. Se roba a la hija de un sacerdote de Apolo, lo que atrae la peste como castigo; después de muchos estragos en las filas del ejército, Agamenón accede a devolver la joven a su padre. Cientos son los soldados muertos víctimas de la enfermedad. Sin embargo, no hay en Agamenón ningún sentimiento de culpa; por el contrario, apenas se retira el sacerdote con su hija, Agamenón comete otra acción infame: despoja a Aquiles de su esclava más querida. Caen nuevos males en el campo de los griegos cuando Aquiles se niega a seguir combatiendo, pero Agamenón se niega a devolver la muchacha. El mismo Agamenón no sintió culpa ni siquiera cuando sacrificó a una de sus hijas, Ifigenia.

\section{LA CULTURA DE CULPABILIDAD}

Son tres los rasgos que, según Dodds, definen la cultura de culpabilidad y el papel del ser humano en ese nuevo contexto.

\section{1 la condición desvalida}

Un primer rasgo de la cultura de culpabilidad es "la conciencia más viva de la inseguridad humana y de la condición desvalida del hombre" (Dodds, 1997: 40), frente a una divinidad dominante y celosa de la felicidad humana. Esta determinación se encuentra desde antes, pero adquiere ahora una especie de acento desesperado, "un énfasis nuevo y amargo en la futilidad de los propósitos humanos". Esto se evidencia, por ejemplo, en el concepto de phthonos o envidia de los dioses: la sensación de que la divinidad es reacia a aceptar la felicidad en 
los hombres. La felicidad puede producir exceso de complacencia, lo que trae como consecuencia el ajuste divino contra la soberbia. La envidia de los dioses adquiere entonces un carácter moral: es peligroso ser feliz. En consecuencia, el temor a los dioses aumenta y las actitudes humanas se contienen para no despertar ese phthonos, limitando de cierto modo las ansias de felicidad para no provocar la ira divina.

En la cultura de vergüenza, por el contrario, las acciones humanas no están delimitadas por ningún temor específico; y cuando de ellas deriva un castigo, esto ocurre sin afectar la conciencia de los hombres. Por eso los héroes homéricos son siempre iguales a sí mismos.

\subsection{Zeus, agente de justicia}

El segundo rasgo, derivado del primero, consiste en transformar lo sobrenatural en general y en concebir el papel de Zeus como agente de justicia. La divinidad asume el cuidado del bien y el castigo del mal en el mundo, como respuesta a la exigencia de justicia que se plantea: "El hombre proyecta al cosmos su propia exigencia de justicia social, y cuando de los espacios exteriores vuelve a él el eco engrandecido de su propia voz prometiéndole castigo para los culpables, saca de éste valor y seguridad" (Dodds, 1997: 40). Un aspecto particular del papel justiciero de la divinidad se manifiesta en el castigo especial que se prevé para los delitos contra los padres. Zeus protege a todas sus criaturas, a pesar de que los hombres siempre se están quejando de la divinidad, como lo dice su voz tronante en la Odisea:

¡Ay, ay, ay! ¡Cómo acusan a los dioses, en estos, nuestros días, los mortales! Dicen que por nosotros son sus males, aunque son ellos mismos quienes buscan, con sus insensateces, las desgracias, y en contra del destino prefijado.

Es la acción humana la que, en últimas, llama a la acción divina o se provee de sus propias desgracias. Sin embargo, el hombre es consciente de que el mal se extiende en el mundo sin que, aparentemente, reciba un castigo. Como decían los cristianos españoles en su lucha contra los moros, abrumados por el triunfo de los infieles musulmanes sobre los protegidos de Dios: "Que Dios protege a los malos / cuando son más que los buenos".
Pero la actitud griega deriva en otra formulación, la de la culpa que se extiende hacia las generaciones futuras como maldición heredada: "El pecador que salía con éxito en su vida sería castigado en sus descendientes, o [...] pagaría su deuda personalmente en otra vida" (Dodds, 1997: 44). La primera opción es la que se generaliza, concebida como culpa heredada, la cual se caracteriza por el castigo al inocente por la falta cometida por el criminal. Aquí se involucra el carácter solidario de la familia griega, que va desde la solidaridad en la sangre, en el honor, en el dolor y en la culpa que se hereda. La acción individual no es suficiente para la felicidad y la virtud y, por lo tanto, la responsabilidad personal no alcanza a ser considerada como factor que pueda emerger en la constitución de la persona, con deberes y responsabilidades distintos a los de la familia.

Como agente de justicia, Zeus pierde los rasgos de humanidad que lo habían caracterizado. Ya no está interesado sólo en su propio bien, como en la época homérica, sino que se constituye en juez de los actos humanos. Como fuerza más abstracta, la divinidad es ahora inspiradora de temor. Este "temor de Dios" se convierte así en una virtud.

\subsection{Contaminación y purificación}

Finalmente, el tercer rasgo se relaciona con "el temor universal de contaminación (miasma), y su correlato, el deseo universal de purificación ritual (khátharsis)". La khátharsis se ritualiza y se hace más compleja. Si en la época homérica la contaminación no implicaba una culpa indeleble, en la época arcaica el miedo a la contaminación se generaliza por el carácter vago de la misma y sus orígenes indeterminados. La contaminación no parece depender de una acción intencional que la produzca sino de una casualidad o una herencia desconocida. La necesidad de castigo y purificación se entiende como consecuencia de nuestro origen y no por una culpa individual. La razón parece estar en la idea de una condición de culpabilidad original de la raza humana.

En el concepto de contaminación se funden las ideas de "contaminación, maldición y pecado", lo que lo convierte en un factor realmente poderoso que infunde terror en la conciencia humana. Al perderse la noción de causa identificable, la contaminación abruma al hombre griego y lo obliga a desarrollar ritos muy complejos para limpiar la 
culpa innominada. De allí a la aparición de la idea de "expiación" se llega por transformaciones claramente explicables.

Una de esas trasformaciones se evidencia en el concepto de ate (comportamiento irracional). Si primero significaba un castigo y señalaba el estado del espíritu pecador, ahora se extiende al producto de ese estado, sinónimo de "ruina" determinada por fenómenos sobrenaturales, $y$ al instrumento de esa ruina, Ate. Un caso especial de ate es el que explica el comportamiento irracional y la ruina como producto de una maquinación a veces divina que hace perder el juicio a los hombres para aumentar las desgracias. Así, es fácil tomar el mal por bien, lo que resulta en una mente envuelta en su propia maraña de engaños. Es comprensible, entonces, como lo señala Dodds, que aun los mejores propósitos terminen en una desgracia ahondada por el deseo vehemente de salir de ella (v. gr., Edipo). El ser humano llega a ser instrumento del ate, lo cual es causa permanente de zozobra.

A lo anterior se agrega la aparición de demonios cada vez más específicos, que promueven el ate, y la demonización de algunas pasiones y actitudes. Así, la esperanza y el miedo son "demonios peligrosos"; Eros es "un poder que pervierte al mal a la mente justa para su destrucción". Estos demonios son externos a la conciencia y actúan sobre ella como entes vivos y poderosos. Otros demonios se constituyen en representación del destino inexorable que determina la vida de un individuo, como especie de demonio personal, ligado de modo indisoluble a su gloria o a su ruina como cualquiera otra de sus virtudes. En la evolución de esta idea aparece a veces como destino puro, voluntad divina o razón pura.

En el paso de una cultura a otra un cambio cultural específico es el "innegable aumento de la ansiedad y del temor en la evolución de la religión griega" (Dodds, 1997: 44), ejemplificado en la acentuación de conceptos tales como el de contaminación y purificación, y la descripción del celo divino como el sustrato del devenir histórico. Además, los conflictos sociales produjeron cambios que realzaron los sentimientos ocultos en la mentalidad griega y generaron una sensación de inseguridad que se manifiesta en el crecimiento del temor personificado en demonios y destinos prefijados. La percepción de la injusticia social pudo haber producido la creencia en una justicia divina que reivindique los males y castigue las culpas. En resumen, la estabilidad social se hace precaria y esa precariedad se manifiesta en la visión de mundo y en las prácticas religiosas.

Otra explicación, que Dodds considera muy justa, se refiere a la degradación de la familia patriarcal y a la disolución de la autoridad paterna: "Mientras permaneció inconmovible el antiguo sentimiento de la solidaridad de la familia, el sistema probablemente funcionó" (Dodds, 1997: 57). Al perderse el vínculo fuerte de los lazos familiares, las tensiones al interior de la célula básica de la sociedad crecen y la estabilidad social sufre en consecuencia. Eso explica que los crímenes que afectan a la familia, como el parricidio, son objeto de culpas que sólo pueden expiarse del modo más trágico posible, en lo individual, lo religioso y lo social. Se debe tener en cuenta que en el mundo griego, al igual que en culturas posteriores, el padre terrenal tiene un correlato divino: Zeus es el padre de los hombres. El rompimiento del carácter sagrado del vínculo familiar se comprende en parte por la aparición del individualismo, que implica el surgimiento de la voluntad y la responsabilidad.

\section{DE LA CULPA A LA JUSTICIA EN LA ORESTÍA}

En Agamenón, la primera pieza de La Orestía, única trilogía completa que se conserva de Esquilo, se inicia la visón trágica de la maldición de los Atridas. El antecedente, del cual no se ocupa Esquilo, puede resumirse así en una de las versiones:

Tántalo, hijo de Zeus, mata a su hijo Pélope y lo ofrece en banquete a los dioses, por lo que fue arrojado al Tártaro para su suplicio. Zeus hace resucitar al niño y le pone un hombro de marfil para remplazar el que Deméter alcanzó a comerse. Al crecer, Pélope pretende a Hipodamia, hija del rey Enomao, para lo cual debe vencerlo en un torneo de carros. Invocando la ayuda de Poseidón y sobornando a Mirtilo, hijo de Hermes y conductor del carro del rey, Pélope vence y mata a Enomao, se casa con Hipodamia y regresa a Frigia. Pero Mirtilo, que está enamorado de Hipodamia, trata de violentarla, por lo que Pélope lo arroja al mar. Mirtilo invoca a su padre pidiendo venganza. Entonces Hermes maldice a Pélope y se declara 
enemigo de sus descendientes. Los hijos de Pélope, Tiestes y Atreo, a quienes corresponde regir la ciudad de Micenas, se enemistan, lo que lleva al primero a raptar a la mujer del segundo. Atreo, en venganza, comete una acción horrible: mata a los hijos de Tiestes y los ofrece luego al padre en un banquete. Según las normas en vigor, este acto infame exige una nueva venganza, por lo que una maldición pesa sobre los descendientes de Atreo. El final de uno de sus hijos, Agamenón, es el comienzo de la trilogía.

Entre las muchas acciones ya señaladas de Agamenón, la muerte de un ciervo consagrado a Artemis provoca la ira de la diosa, que exige en retribución el sacrificio de Ifigenia, la hija del rey, para el éxito de la expedición a Troya. El conflicto entre su deber como guerrero (contribuir al éxito de la empresa) y su amor paterno es puesto en escena:

Penoso es mi destino si no obedezco, y penoso también si doy muerte a mi hija, orgullo de la casa, manchando ante el altar mis manos paternas con arroyos de sangre virginal. ¿Cuál de las dos acciones está libre de males? ¿Cómo puedo dejar las naves, faltando a mi alianza?

Y en la Antistrofa 3 se responde: "Sea para bien". La muerte de Ifigenia, tal como la presenta Esquilo, implica ya la conciencia de una culpa en el conflicto entre el deber personal y el deber común, conflicto que es irresoluble porque la disyuntiva no ofrece un camino libre de infamia y de nuevas culpas. A pesar de las súplicas de Ifigenia, Agamenón ordenó a los siervos que la sacrificaran "a manera de cabra". Se le cubre la boca -la misma con que cantara en los banquetes en honor a Zeus y a la gloria de su padre- para no oír sus lamentos. Se trata de una historia traída de la época de la "cultura de vergüenza" vista a la luz de la "cultura de culpabilidad", con su componente de culpa heredada, vaga e indeleble, tal como se resume en la Antistrofa 4:

Porque a los mortales les anima la demencia insolente, torpe consejera, causante de desgracias. Él, pues, se atrevió a hacerse sacrificador de su hija, ayuda en una guerra para vengar una mujer $y$ ofrenda por las naves.

Al regreso de Agamenón a su patria, Clitemnestra da testimonio público de amor a su marido y de paciente espera, pero en su conciencia ya ha anidado la venganza por el sacrificio de su hija, para lo cual cuenta con la ayuda de Egisto, su amante y usurpador del trono. Casandra, a quien Agamenón ha traído desde Troya, se refiere a los males sangrientos de la casa de los Atridas y predice la venganza de Orestes, continuación de la serie vindicadora. Después de asesinar a su esposo, Clitemnestra responde al reproche del corifeo:

Ahora me condenas al destierro, a soportar el odio de los ciudadanos y a las maldiciones del pueblo. Entonces nada hiciste contra este hombre que, sin importarle, como si se tratara de la muerte de una res entre innumerables ovejas de lanudos rebaños, sacrificó a su hija, el más querido de mis partos, para encantar los vientos tracios.

Luego pone su acción en manos de los dioses.

En contraste con Esquilo, en el relato homérico se ignora la muerte de Ifigenia como motivo de la venganza; la muerte de Agamenón ocurre durante un banquete, junto con todos sus compañeros, a manos de Egisto.

Esquilo toma este sacrificio como móvil que impulsa a la homicida, y de este modo brilla el acero matador como un relámpago de venganza celeste y con un rayo de amor maternal. En vez de perecer entre el desorden de un banquete sangriento, el héroe cae teniendo un pie en el baño, envuelto, como en una red de pesca o de caza, en el lienzo que su mujer ha lanzado sobre él; y este degollamiento a ojos cerrados, este asesinato doméstico, es más espantoso que el tumulto de una gran matanza (Saint Victor, 1946: 288).

Así nace lo trágico: aparece lo personal, la motivación en la cadena de crímenes. La venganza sigue; por eso es la mano de Clitemnestra, madre de Orestes, la que mata y no Egisto, el usurpador. Como advierte el Corifeo: "La Moira, a la vista de un nuevo crimen, afila en otras piedras su Justicia", y "quien despoja es despojado y el que mata paga su deuda". Zeus es el agente de esa concepción vindicativa de justicia.

En Las Coéforas se cumple la segunda parte de la serie vindicativa. Clitemnestra, acosada por un terrible sueño (ha parido una serpiente que debe amamantar hasta hacerle sangrar el pecho), envía 
a su hija Electra a rendir tributo sobre la tumba de Agamenón. Electra duda si pedir venganza, tal como la instruye el corifeo:

Electra: ¿Qué pediré? Instruye a una inexperta, explícame.

Corifeo: Que venga contra ellos algún dios o mortal.

Electra: ¿Hablas de un juez o de un vengador? Corifeo: Di sencillamente: alguien que mate a su vez.

Electra: ¿Es piadoso que pida esto de lo dioses? Corifeo: ¿Cómo no devolver mal por mal a los enemigos?

Entonces pide venganza por la muerte de su padre y la desgracia para su madre y Egisto. Orestes ha llegado primero a la tumba de su padre y en el encuentro los dos hermanos se deciden por la venganza, exigida por Apolo. El Corifeo contribuye al dramatismo con su insistencia: "Que un golpe mortal se expíe con otro golpe mortal; el que así ha obrado así sufra, reza una máxima tres veces vieja".

Electra se pregunta si no es invencible Ate, divinidad del error que se posa sobre las cabezas de los hombres, la ciega pasión que los induce al mal y al error. El Coro responde: "El pasado es así; el futuro apréndelo de tu ira".

Interpretando el sueño de su madre como un mandato para darle muerte, Orestes y su amigo Pílades urden una estratagema para engañar a Clitemnestra y a Egisto. El Corifeo hace parte de la estratagema, indicándole a la Nodriza que diga a Egisto que venga solo al encuentro con Orestes. En el momento supremo, Orestes duda y pide a Pílades consejo sobre si matar o no a su madre. Pílades le dice: "Hazte enemigo de todos antes que de los dioses". Clitemnestra se justifica en la consumación de un acto que obedece a una ley antigua: "El Destino, hijo, ha tenido su parte de culpa". Pero Orestes le responde: "Entonces también el Destino ha preparado tu muerte". Orestes mata a los dos, pide comprensión y enloquece por el acoso de las Erinias vengadoras de su madre.

El Corifeo anuncia el fin de la cadena indefinida de venganzas: "¿Cuándo terminará, cuándo se detendrá, por fin, adormecida, la cólera de Ate?”. En Las Euménides, última pieza de la trilogía, se representa el proceso de reconciliación en el que se resuelve la ley de la venganza. Orestes, perseguido por las Erinias vengadoras, es protegido por Apolo y Atenea, quien convoca el tribunal que dará fin a la tragedia de la venganza indefinida. Atenea se dirige así al pueblo:

Escuchad ahora la norma que instituyo, pueblo de Ática, que vais a resolver la primera causa por sangre derramada. Este Consejo de jueces permanecerá siempre en el futuro entre el pueblo de Egeo [...]. Ni anarquía ni despotismo: tal es la máxima que aconsejo a los ciudadanos mantener con reverencia y no desterrar enteramente de la ciudad el temor. ¿Qué mortal se mantiene en la justicia, si nada teme? Venerad como se debe este poder augusto y tendréis un baluarte salvador de vuestro país y vuestra ciudad, como nadie lo tiene [...]. Incorruptible, venerable, severo, tal es el Consejo que instituyo, guardián de la tierra, siempre despierto en defensa de los que duermen.

Apolo se vale de un sofisma para defender a Orestes: "No es la madre quien engendra al ser que llama hijo; sólo es alimentadora del germen depositado en su seno. El que engendra es el padre: la madre recibe el germen y lo conserva, si los dioses lo consienten". Para la armonía y el fin de la sangre este sofisma vale, como cualquiera otro, pues es clara la intención de Esquilo: La justicia de inspiración divina es la única capaz de dar fin a la culpa indeleble, la que restituye la concordia y derrota a Ate. El voto de calidad de Atenea resuelve a favor de Orestes el empate en la decisión del Consejo, lo cual es signo de que la Justicia se relativiza para romper la cadena indefinida de retaliaciones.

Si Orestes hubiera sido condenado, de todos modos se detendría la cadena de venganzas porque habría sido muerto por decisión de un tribunal. Las palabras finales del cortejo dan fe de la armonía recuperada: "Y la paz, para la felicidad de sus hogares, reside hoy con los ciudadanos de Palas; Zeus, que todo lo ve, y la Parca, están de acuerdo. Y ahora lanzad gritos de alegría mientras danzáis".

Con el tribunal de Atenea, las Erinias sienten perdido su poder, basado en antiguas leyes eternas e infalibles. En sus orígenes, las Erinias, divinidades anteriores a Zeus, eran guardianas del orden natural, personificaciones de la Aurora. "Pero esta 
significación natural desapareció prontamente, en Grecia, bajo un sentido moral. Allí, desde el punto en que surgieron, las Erinias personificaron el remordimiento y el castigo" (Saint Victor, 1947: 322).

Atenea logra convencer a las Erinias y abolir el talión. En adelante se las llamará Euménides, "las buenas doncellas". La reconciliación cierra la tragedia y las bendiciones para Atenas son pacto de paz. El crimen de uno solo ya no compromete a su estirpe, como ocurre en la "cultura de culpabilidad". Se funda la Justicia humana de inspiración divina.

Paul de Saint Victor lo explica así:

\begin{abstract}
El hombre no corrige sus leyes sino después de haber corregido sus dioses. Toda su vida social y moral lleva la huella de la imagen que de ellos se forma [...] Para que la humanidad quedase exenta de las tradiciones de muerte que sobre ella pesaban, era preciso que unos dioses mejores la colocasen por encima de las divinidades feroces de los antiguos tiempos. También era preciso que esas divinidades de terror, colocadas en categoría subalterna pero no abolidas, se transformasen en consonancia con el nuevo orden de cosas. La conversión de las Erinias, metamorfoseadas en Euménides, representa, en símbolo sorprendente, el progreso de las religiones enmendadas por el hombre (Saint Victor, 1947: 351)
\end{abstract}

\section{CULPA Y CONFLICTO}

En la tragedia griega incluso los muertos tienen pasiones que se extienden a los vivos e influyen en sus actos. En Las Coéforas dice el Coro: "El muerto clama y su voz delata al asesino. Entonces el justo duelo de los antepasados y de los padres impulsa por todas partes a los hijos a la venganza". Por eso la sombra de Clitemnestra reprocha a las Erinias que hayan dejado escapar a Orestes. Antes de la intervención de Atenea y Apolo, el principio de culpa heredada, causante del conflicto, no parece tener salida: "La sangre derramada pide sangre. Erinia grita y quiere muerte por muerte".

Sin embargo, el conflicto es necesario para marcar la necesidad de extraer de los desencuentros material que dé sustento a la vida. La tragedia nos presenta conflictos que no pueden ser resueltos por apelación a una norma externa porque las visiones encontradas no son compatibles en ninguna tradición. Se ahonda en los conflictos no para resolverlos sino para comprenderlos en profundidad, para acentuar los rasgos de humanidad y para derivar de ellos un bien mayor, como lo expone Julián Serna:

Porque el poder de los dioses griegos es un poder repartido, los conflictos no sólo se hacen posibles, sino además probables. Porque entre ellos también se reparte la virtud y el vicio, las divinidades de los politeísmos no son del todo buenas ni del todo malas. Los dioses pueden ser magnánimos, ecuánimes, leales, pero también pueden ser lo contrario. Los mitos en los que es posible registrar la infidelidad, la maquinación, el engaño de los dioses son legión. Pero son justamente esas divinidades iniciadas en el mal las que estarían en condiciones de utilizarle como medio para un bien mayor, de introducir periódicas cuotas de caos en el cosmos para garantizar la diversidad, la incertidumbre necesaria para sacar adelante el proyecto de hombre como un ser abierto a sus posibilidades, es decir, como un ser con futuro (Serna, 2002: 21).

Para el héroe trágico cada opción implica un compromiso con el pasado y con el destino, y no existen opciones ciertas o confortables. Para Lukács, la tragedia es "una representación del hombre y del destino", en la cual "el hombre sabe de su destino y llama culpa a ese saber" (Lukács, 1985: 261). Por ello la tragedia puede estar más cercana a la vida que las reflexiones racionales acerca de su sentido: "La vida es una anarquía del claroscuro: nada se cumple del todo en ella y nada llega a su fin" (244). Ese carácter no conclusivo de la tragedia es el que determina su permanencia como metáfora de la vida.

En el planteamiento del conflicto la palabra adquiere protagonismo en el diálogo dramático. La palabra del héroe trágico "se encamina hacia un objeto visible, su pasión ataca a un ser viviente, en vez de abrazar en el vacío a una Sombra evocada por el encantamiento de un relato" (Saint Victor, 1947: 71). Como explica Jesús Ferro:

El instinto metafórico conduce al hombre hacia el arte, porque no concibe como real más que la vida disfrazada de apariencia y de belleza. El hombre teórico, así como el hombre intuitivo, desean dominar la vida, pero el hombre intuitivo lo hace más victoriosamente que su adversario: el dominio del arte se funda en la vida (Ferro, 1984: 31). 


\section{CONCLUSIÓN}

En la cultura griega se produjo una transformación religiosa y moral mediante la cual el concepto de culpa apareció como componente del pensamiento general, que luego se extendió a la filosofía, la reflexión moral y la literatura. El concepto es por sí mismo profundamente significativo para la descripción del pensamiento religioso griego y su influencia en la visión de mundo del hombre occidental.

En general, puede afirmarse que es la irrupción de la personalidad individual, contrapuesta al mundo homérico perfectamente cohesionado, la que empuja esos cambios en la medida en que el individuo es cada vez más consciente de su destino personal y de su vinculación con una divinidad cada vez más lejana. Al perder los vínculos que lo ligan al grupo social y a la familia, donde el espíritu individual encuentra refugio y las debilidades se diluyen, el hombre griego se debe enfrentar solo a su destino.

La tragedia griega, por el dialogismo que la caracteriza, ofrece el espacio privilegiado para representar ese tránsito de la vergüenza a la culpa, del orden al conflicto, del mundo tutelado al de la acción responsable.

\section{REFERENCIAS BIBLIOGRÁFICAS}

Berlin, Isaiah (1992). El fuste torcido de la humanidad. Capítulos de historia de las ideas. Barcelona: Península.

Dodds, Eric R. (1997). Los griegos y lo irracional. Madrid: Alianza.

Dworkin, Ronald (1994). El Dominio de la Vida. Barcelona: Ariel.

Esquilo (1978). "Tragedias". En Teatro griego. Madrid: Aguilar. Ferro, Jesús (1984). Nietzsche y el retorno de la metáfora. Barranquilla: Ediciones Uninorte.

Hare, Richard M. (1963). Freedom and Reason. Oxford: Clarendon Press.

Hospers, John (1964). La Conducta Humana. Madrid: Tecnos.

Kant, Immanuel (1998). Fundamentación de la Metafísica de las costumbres. México: Porrúa.

Locke, John (2001). Carta sobre la Tolerancia. Madrid: Mestas. Lukács, Georg (1985). "Metafísica de la tragedia". En El alma y las formas. México: Grijalbo.
Míguez, José Antonio (1978). "Introducción”. En Teatro griego. Madrid: Aguilar.

Mill, John S. (1994). Utilitarismo. Barcelona: Altaya.

Nietzsche, Federico (1973). El nacimiento de la tragedia. Madrid: Alianza.

Nozick, Robert (1990). Anarquía, Estado y Utopía. México: F. C. E.

Parfit, Derek (1984). Reasons and Persons. Oxford: Oxford University Press.

Popper, Karl (1997). El Mito del Marco Común. Barcelona: Paidós.

Rawls, John (1986). Justicia como Equidad. Madrid: Tecnos.

Rawls, John (1997). El Liberalismo Político. México: F. C. E.

Rawls, John (1972). A Theory of Justice. Oxford: Oxford University Press.

Saint Victor, Paul de (1947). Las dos carátulas. Tomo I. Buenos Aires: Ediciones Anaconda.

Serna, Julián (2002). "Tragedia, paraíso y utopía". En Finitud y sentido. Colección Discusiones 1. Pereira: Publiprint.

Singer, Peter (1991). Ética Práctica. Barcelona: Ariel.

Singer, Peter (2002). Una vida ética. Madrid: Taurus.

Thomson, Garrett (1987). Needs. Londres: Routledge \& Kegan Paul.

Trigg, Roger (1973). Reason and Commitment. Londres: Cambridge University Press.

Williams, Bernard (1982). Introducción a la Ética. Madrid: Cátedra. 